\title{
Investigating Young Children's Social Interactions During Digital Play
}

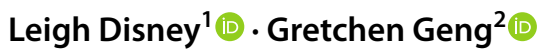

Accepted: 2 October 2021 / Published online: 17 October 2021

(C) The Author(s), under exclusive licence to Springer Nature B.V. 2021

\begin{abstract}
In digital play, social interactions have aroused much debate among early childhood stakeholders, particularly in the areas of young children's social learning and their domains of development. The main concern of early childhood educators is the limits of children's social interactions occurring in digital play. This study used a four-week semi-structured field observation of eighty 3-4-year-old children within three Australian childcare centres to investigate children's social interaction whilst involved in digital play using iPads. Seven different forms of social interactions were identified during children's digital play. Furthermore, it was found that although children showed high levels of engagement during digital play, only observing others does not always impact children's engagement during digital play. Rather self-reflection influences how children engage and choose their own course of action within digital play. Early childhood educators and parents may find this paper useful in understanding various children's social interactions during their digital play to program effective, appropriate and meaningful experiences for young children.
\end{abstract}

Keywords Social learning $\cdot$ Digital play $\cdot$ Social interactions $\cdot$ Social behaviours

\section{The Concept of Digital Play in This Study}

Children's encounters with digital media in everyday life have been conceptualised, ecologically paving the way for expanded thought regarding digital technology and children (Plowman, 2016). Research on children's everyday engagement with digital technology is becoming more common (Flynn \& Richert, 2015; Plowman et al., 2008), as such the concept of 'digital play' is becoming accepted as a form of play (Disney et al., 2019; Mantilla \& Edwards, 2019; Sakr, 2019; Wood et al., 2020). Different from traditional play activities of young children, digital play has been identified as a context in which young children use digital technologies (Scott, 2021).

In this paper, we conceptualise digital play as children's active use of digital technologies within a play-based

Leigh Disney

leigh.disney@monash.edu

Gretchen Geng

gretchen.geng@acu.edu.au

1 Faculty of Education, Monash University, Melbourne, Australia

2 National School of Education, Australian Catholic University, Melbourne, Australia learning context, and we are most interested in studying children's social behaviours within digital play. We are building on previous research on digital play such as Bird and Edwards (2015) Digital Play Framework, where they situate digital play as a culturally mediated activity for children using cultural tools (such as iPad in this study) and identify a range of digital play types. Other scholars such as Puerling (2018) detail the importance of an integrated curriculum approach when embedding technologies in early childhood to support learning. There is also a growing body of literature on the most effective ways to use digital play with children (Marsh et al., 2016; Scott \& Marsh, 2018; Simon et al., 2012). However, as the use of digital technology by children continues to grow and change, it becomes difficult to predict how it will expand and alter over time and how best to use them within early childhood education (Danby et al., 2018; Donahoo, 2018; Edwards, 2016; Edwards, et al., 2017; Sakr, 2019). Yet, position papers on young children and digital technology, such as that of Early Childhood Australia (Edwards et al., 2018) suggest educators and families need to consider what constitutes appropriate digital technology use.

There appears a confusion among early childhood educators on how to conceptualise digital play. For example, there are fears from early childhood stakeholders that 
digital technology use can be addictive and socially isolating, potentially fostering negative social and emotional outcomes, inhibiting language development and developing poor communication skills that are needed for school and beyond (Plowman \& McPake, 2013; Zabatiero et al., 2018). Not surprisingly then, there is debate over the place of digital technology in the lives of young children (Johnston et al., 2018; Mantilla \& Edwards, 2019; Straker et al., 2018). In a sector survey of 515 Australian early childhood educators, Zabatiero et al. (2018) showed that $52 \%$ of respondents stated that they disagreed that digital technology has great potential benefits for young children's learning. Furthermore, qualitative data from the same study indicated that early childhood educators fear 'too much time spent with digital implements reduces social contact' (2018, p. 19). A finding supported by Disney's (2016, p. 134) study where an early childhood educator expressed that rather than the need to integrate digital technology, "the early years and this includes junior primary, needs to focus on the values of creativity, imagination, social, language skills and selfregulation". Thus, there is a need to understand the concept of digital play. Within this paper, the focus is on how children connect socially when they are engaged in digital play to address the above fears or concerns from parents and educators.

\section{Social Learning and Social Interactions in Digital Play}

Social learning theory emphasises children's social behaviour through their observation of others, responding to teachers' or peers' instruction and feedback (Kafai \& Resnick, 1996); and learning is not completed by independent factors, but instead through social influences and neural events (Bandura, 1989, 2001). Young children use their sense of independence to build confidence and selfesteem and acquire positive attention, praise, and opportunities to develop their social competence (Bandura, 1977, 2001). Learners' inner thoughts are shaped by all outer social influences, and modelling or observing others are a major component of social learning theory. Observing others can form new behaviours, and the new information becomes forethought (Bandura, 2001), and children can construct their conceptions of behaviours or influence their own choices directly from observing the effects of the actions of others (Bandura, 2001, 2009). As such, modelling or observing others are common behaviours among young children. Peer support has been found as a crucial part of the learning process, especially through modelling (Bowers-Campbell, 2008), in promoting active learning (Sherman \& Kurshan, 2004). Children establish close relationships with playmates, cooperate with others, participate in group activities, and show the ability to concentrate on and persist at challenging tasks, as well as listen to instructions and be attentive (Ladd \& Ladd, 2019).

Parten (1932) developed the Stages of Play theory, which recognised six types of play: unoccupied play, solitary play, onlooker play, parallel play, associative play, and cooperative play. These six types of play have since been used as the theoretical basis for studies in children's social interaction. Bandura (1978) developed a series of modes of interaction: unidirectional, partially directional, and reciprocal. Although it was agreed at the time these simple deterministic models cannot be ruled out to explain social interactions (Staddon, 1984), there is an undeniable connection, and the discussion of such dynamic interactions are not clearly reflected in young children's observable social behaviours and their impact on their cognitive learning outcomes.

Buggey and Ogle (2013) refined three forms of social interaction being: Initiation, parallel, and engagement. In detail, initiation has purposeful physical approaches and vocalisation. Parallel involves less verbalisation or exchange of play equipment. Finally, engagement refers to either engaged verbal and physical interactions or cooperative exchange of materials during play activities.

Additionally, Bandura (2001) stated that children's interactions include many factors, including learners' own characteristics, their cognitive organisation, motor reproduction, self-observation, timely and accurate feedback, and levels of motivation and reinforcement. These determine that children do not copy everything they observe, and they use self-reflection and inner thought to decide which influence they will take or choose as their own course of action. The period of birth to five years of age sees a rapid growth within all domains of development (Dodge et al., 2002; Garvis et al., 2019), and this development is an intertwining holistic process whereby all domains are interconnected (McDevitt \& Ormrod, 2012). Thus, in a childcare context, children's behaviour is interacted between their own cognitive, and environmental influences, including other children's behaviour.

The previous studies have not addressed children's behaviours during digital play, and how children interact with each other with the implementation of digital technologies. Moreover, the "self" within children's social learning during digital play has not been studied in-depth. This paper, therefore, uses social learning theory to tap into young children's social behaviours, in particular social interaction patterns, in their digital play.

Thus, to have a better and updated picture of social learning interaction during digital play, this research is intended to investigate (a) what are the forms of social interaction activities occurring during their digital play? and (b) 
what are the impacts of these activities on young children's social learning and their engagement levels?

\section{Methods}

A mixed-methods approach of both quantitative and qualitative methods (Ary et al., 2010) has been used in this research study, and this study is a part of a larger-scale study. Denzin and Lincoln (2011) stated that it is possible to conduct observations in settings that are natural loci of those activities that may be the result of a controlled experiment. Moreover, observation is a particularly useful method of data acquisition for early childhood development studies (Suen \& Ary, 2014). Therefore, in this study, semi-structured field observation was used to collect information about children's social learning activities.

Upon ethics approval from an Australian University Ethics Committee (ethics protocol number 000028114), information letters and consent forms were distributed among the participants and their parents in 2014. The researchers contacted ten childcare centres in Australia, and three childcare centres agreed to participate in this study. All children's parents were also informed and consent forms were collected from the children's parents. The study was conducted from 2015 to 2016.

\section{Research Context}

This study was conducted within three Australian childcare centres across two states and territories. One setting was a long daycare centre situated within a primary school, whilst the other two settings are stand-alone community long daycare centres. The three childcare centres were licenced for approximate 45-85 children. All three centres predominately had Diploma trained full and part-time educators. All services had indoor and outdoor programs reflecting appropriate play-based pedagogies aligning with the Early Years Learning Framework (Department of Education \& Training, 2019). All services supported the use of concrete learning materials more than digital technologies, thus, children had limited digital play opportunities. It was noted that on multiple occasions during children's play with the iPads in the study; staff would purposefully restrict children's digital play to a solitary activity. They did this by moving children who were watching or interacting with the playing child away; however, this was not consistent across various settings. At times, when the children were playing with the iPads, there were up to nine other children around and interacting with the participants. They were explaining, discussing, watching, or distracting participants' digital play.
In terms of the participating children's access or "exposure" to various digital technologies within the home, more than $98 \%$ of participating families ( 78 out of the 80 families) allowed their children to have access to the digital technologies at home, particularly iPads and mobile devices. There were no significant differences among the participating children's parents' age, gender and highest qualifications, or children's engagement with digital technology. There were no siblings within the 80 participating children, consequently, each of the 80 parents was different. It was noted that parents who were technologically savvy might teach children technical skills at home, which in turn promoted their children's engagement with digital technology.

\section{Participants}

The use of 3-and 4-year-old children in this study was based upon the following: (a) there are limited studies on the use of digital play in Australian early childhood settings; (b) children younger than 3-years-old learn through their bodies: their eyes, ears, mouths, hands, and legs and that the developmental skills these children are learning to master are crawling, walking, talking, and making friends (Haugland, 2000); and (c) that screen time is not recommended for children 2 years and under (American Academy of Pediatrics, 2011).

Of the 80 children, 44 (55\%) were male, and $36(45 \%)$ were female. Forty (50\%) children were from South Australia, and forty $(50 \%)$ were from the Northern Territory. The age range of the children was from 36 months (above 3 years) to 59 months (under 5 years old). Children were classified as being in the 3-4 years age group (43.8\%), and the $4-5$ years age group (56.3\%). Therefore, there was an even spread of children between the two primary age ranges, which represents a variety of differing developmental capacities related to ages and stages of development. Of the 80 children, 12 children (15\%) were attending child care centre(s) full time (10 sessions per week), 68 children (85\%) were attending child care centre(s) between 4 to 8 sessions per week.

\section{Instrument}

This study investigated children's engagement whilst playing mathematical Apps using the Laevers Child Involvement Scale (Department of Education and Children Services [DECS], 2008). Ebbeck et al. (2012) effectively used the scale to assess the strengths and weaknesses of Singaporean early childhood curriculum by measuring children's engagement within programs. The Involvement Scale describes nine signals that a child participating in an activity 
was indeed 'involved', they include: (1) concentration, (2) energy, (3) complexity/creativity, (4) facial expression and posture (non-verbals), (5) persistence, (6) precision, (7) reaction time, (8) verbal utterances/language, and (9) satisfaction. Each signal had indicators which must be observed and assisted in ranking the signal as low $(l)$, medium $(m)$ or high $(h)$ during observations.

\section{Procedure}

This study took place over a total period of four continuous weeks in each of the participating childcare centres. The researchers introduced themselves to the children and informed them of their research rights and the study in a language they could understand. The participating children had free access to the iPads, provided with facilitation of the adult childcare educators, during this research period. During the first week children were given access to iPads so they were used to using gestural interfaces, after which, purposefully selected educational Apps were installed on each iPad. When children played with the Apps they were observed and their play was recorded using the Involvement Scale (DECS, 2008). All children were observed during their first use, and five times after this, for a total of six observations. Each observation was two minutes in duration; starting at any time whilst the child was using the iPad and continuing for two minutes. If the child left the iPad during the two-minute observation period, the researchers continued to observe the child in case they returned to the iPad.

When children were playing with the Apps, there were up to nine other children around and interacting with the participants. They were explaining, discussing, watching, or distracting participants' play and these interactions were recorded within the Involvement Scale's notes section. The researcher's observations of non-participating, yet observing, children's interactions with participating children were coded to identify themes of social interaction behaviour, according to the instruction of the Involvement Scale (DECS, 2008) and the three categories of interactions defined by Buggey and Ogle (2013). In addition, during digital play, the researcher wrote down pertinent observations of children's engagement that may influence their engagement.

\section{Data Analysis}

The quantitative analysis of qualitative data can be done by coding ethnographic data and looking for emerging patterns (Silverman, 2014). Statistical Package for Social Science (SPSS) were used and alpha was set at 0.05 .

In terms of the qualitative data collected from observation, the researchers summarised their observations based upon the Involvement Scale following the observation rules. The two researchers then actively engaged themselves in critical self-reflection about their own potential biases; thus, reflexivity was used to ensure researchers became more aware of their potential predispositions to monitor and attempt to control their biases (Johnson \& Christensen, 2014). The two researchers used the analysis proceeding by visiting and revisiting the data and connecting these with in-depth and emerging insights, which consequently led to the focussed understanding of seven categories and themes identified from the observations (Punch, 2009) based upon initiation and engagement (Buggey \& Ogle, 2013). In addition, the number of children observing participating children's iPad use during one observation session was characterised by using means and standard deviations. Quantitative data collected were then entered into the SPSS, and alpha was set at 0.05 for the purpose of the present study.

\section{Findings}

Table 1 presents the means and standard deviations of the nine areas within the Involvement Scale (DECS, 2008). It was found almost all the areas other than verbal utterances and language were rated above medium engagement. Among these, the areas of facial expression and posture, persistence, and concentration were rated closer to high engagement. A repeated-measures ANOVA was applied across the 9 frequencies. A significant effect was evident (see Table 1). This suggests that all areas in the engagement scale were discriminating effectively between the items. This indicates that the nine areas are interrelated, therefore engagement with digital technologies is a holistic process for children.

The participating children were divided into "the playing children" (the ones who were operating the iPad) and "the non-playing children" (the ones who were interacting or observing the child using the iPad). All participating

Table 1 Engagement of children's playing apps (means)

\begin{tabular}{llll}
\hline & Mean & $S D$ & $N$ \\
\hline Facial expression and posture & 2.90 & 0.47 & 80 \\
Persistence & 2.83 & 0.50 & 80 \\
Concentration & 2.80 & 0.47 & 79 \\
Reaction time & 2.50 & 0.57 & 80 \\
Precision & 2.39 & 0.65 & 80 \\
Satisfaction & 2.26 & 0.51 & 80 \\
Energy & 2.23 & 0.50 & 80 \\
Complexity and creativity & 2.05 & 0.37 & 80 \\
Verbal utterances and language & 1.79 & 0.64 & 80 \\
\hline
\end{tabular}

${ }^{a}$ The means were presented in order, from highest to lowest, using 4-point scale anchored $(0=$ no engagement, $1=$ low engagement, $2=$ medium engagement, and $3=$ high engagement)

${ }^{\mathrm{b}} \mathrm{A}$ repeated measures ANOVA on the above means revealed a significant effect, $\mathrm{F}(8,624)=90.17, \mathrm{p}<0.01$ 
children's behaviours were coded to identify themes of behaviour based upon frameworks (Buggey \& Ogle, 2013): Initiation, parallel, and engagement. The researchers also categorized the three modes of social behaviours by identifying the playing children and the non-playing children. Social interaction behaviours were coded and classified into the following seven categories. To clarify each category, one example scenario of each interaction was included.

- Other (non-participating) children initiate involvement in play (SI1)

- The player involves other (non-participating) children in playing (SI2)

- Other (non-participating) children distract play through initiating other activities (SI3)

- The player distracts other (non-participating) children during playing (SI4)

- The player ignores other (non-participating) children's engagement (SI5)

- The player stopped other (non-participating) children's interruption (SI6)

- The player's private speech during playing (SI7)

\section{Social Interaction [SI]1: Other (Non-participating) Children Initiate Involvement in Play}

SI1 was categorised if children who were non-participants attempted to engage participants about the game being played. This interaction pattern was found between 0 and 6 times per child observation. The following text shows an example of the other children initiating involvement in play:

Child No. 23 was playing the App Monkey Numeracy. The App asked Child No. 23 to connect the dots from number 1 to the number 7 . The participant needed to touch 1 and then drag a line to the number 2 , to 3 and so on, moving along until they finish at 7 (at which point a turtle traverses the path created and calls out the numbers). Child No. 23 was struggling to use the interface and appeared not to understand that there was a need to drag from one number to another; he was touching 1 then touching 2 without using a drag function, then would touch the turtle then touch a number. A child sitting next to Child No. 23 reached out to the iPad, placed his finger on number 1 , then dragged the line to number 2 and said, "That's how you do it," and smiled at Child No. 23.

Child No. 23 was engaged in digital play Although struggling to use the interface, he did not ask for help. Rather, the observing child, who clearly had more knowledge of the requirements of the game, initiated the interaction with a physical behaviour (using finger on the iPad) and followed this up with a facial gesture and verbal interaction. It was observed that this interaction was initiated by the child without the iPad, and thus, it is classified into SI1.

\section{SI2: The Player Involves Other (Non-participating) Children in Playing}

SI2 was categorised if children were participating in a game and there was an attempt to engage another child in their game by making the first advance. This interaction pattern was found between 0 and 6 times per child observation. Observation of Child No. 21 shows an example of the player involving another child in play:

Child No. 21 was playing the App Intro to Numeracy. The child was sitting at a table with the iPad in front of her. The game that Child No. 21 was playing was a numeral copying game, she was attempting to trace the number 4. Child No. 21 had only completed half of the tracing of the number 4 , and the App was prompting her to finish moving across the screen to complete the horizontal stroke, however she was attempting to move down the screen vertically to finish the number (the App will not let the participant move forward until the numeral is completed). Child No. 21 appeared quite frustrated and looked at an older child standing near her and said, "I can't do this, can you help me?" and moved the iPad closer to him. The older child looked at the screen (the App was still prompting), he then completed the task, and the App moved to the number 5. The older child smiled at Child No. 21 and moved the iPad back in her direction, Child No. 21 smiled back and said "Thanks"! In this case Child No. 21 sought the assistance of the older child to solve a problem she was having.

Child No. 21 was engaged in digital play. SI2 is similar to SI1; however, the initiation came from the player, not the observing child. In the example, Child No. 21 asked for help by saying "I can't do this, can you please help?" Child No. 21 also initiated a physical movement to another child by sitting closer. The observing child responded by helping Child No. 21 complete the tasks. Thus, this social behaviour is classified as SI2. 


\section{SI3: Other (Non-participating) Children Distract Play Through Initiating Other Activities}

SI3 was categorised if children were participating in a game and there was an attempt to distract them with information not pertaining to the game or iPad use. This interaction pattern was found between 0 and 4 times per child observation. The following shows an example of a child being distracted during gameplay:

Child No. 17 was seated inside playing the App Bugs and Bubbles, another child came from the outdoor environment as said to Child No. 17 "come to the sandpit we've built a monster hole". Child No. 17 looked in the other child's direction and replied "yeah, I'll be there when I finish my game" and turned his attention back to the iPad and continued playing the game.

In this example, one child was engaged in digital play, while the other one was not. This example showed a distraction of the participant during digital play, as the non-participating child asked Child No. 17 to "the sandpit". There was social interaction between the two children, as Child No. 17 responded by "I will be there when I finish...", therefore distracted within his digital play. This type of behaviour is then classified as SI3.

\section{SI4: The Player Distracts Other (Non-participating) Children During Playing}

SI4 was categorised if the child was using the iPad and during their play discussed non-iPad related information with another child. This interaction pattern has been found between 0 and 3 times per child observation. Observation of child No. 52 shows an example of the player distracting another child during play:

Child No. 52 was sitting at an outside bench with an iPad playing the App Bugs and Bubbles. A child rode a bike past the bench where Child No. 52 was using the iPad. Child No. 52 looked up from his game and said to the child on the bike, "hey, that's my bike". The child on the bike looked back at Child No. 52, put his feet on the ground and asked "can I use it"? Child No.52 replied "okay, but once I've finished this [referring to the iPad], I want it back".

In this social interaction, one child was engaged in digital play, and the other was not. The distraction came from the player, not the other child. In this example, Child No. 52 initiated the conversation by checking who was riding his bike. Their conversation was engaging, but not about digital play. Thus, this social behaviour is classified as SI4.

\section{SI5: The Player Ignores Other (Non-participating) Children's Engagement}

SI5 was categorised if the child was using an iPad, and during their play, another child attempted to interact with the child regarding gameplay or iPad use, and the child did not appear outwardly to acknowledge the child's attempted engagement. This interaction pattern was found between 0 and 6 times per child observation. Observation of child No. 24 shows an example of the player ignoring another children's engagement:

Child No. 24 was playing the App Counting Bees. To her right, was Child No. 37, who was watching Child No. 24 play. Child No. 24 was watching the bees float across the page; she did this for about 10 seconds when Child No. 37 looked at Child No. 24 and said, "you have to move the bees to the flowers, do you want me to show you?" Child No. 24 did not look at or say anything to Child No. 37 and continued to watch the bees; Child No. 37 reached in and moved one of the bees towards the flower, causing the App to call out 1. Child No. 24 again did not acknowledge Child No. 37's actions nor touched the screen. Child No. 24 then pressed the 'home button on the iPad and exited the Counting Bees game.

In this social interaction pattern, although both of them were engaged with the digital play concept, there was no mutual engaged moment between them. In the example, Child No. 37 tried to initiate a conversation by saying "you have to move... do you want me to show you...?" However, Child No. 24 did not respond to or acknowledge the initiation from the No. 37. This type of behaviour is then classified as SI5.

\section{SI6: The Player Stopped Other (Non-participating) Children's Interruption}

SI6 was categorised if the child was using an iPad and during their play, another child attempted to interact with the child and the child verbally requested the interacting child to stop their interruption. This interaction pattern was between 0 and 5 times per child observation. Observation of child No. 32 shows an example of the player stopping other children's interruption.

Child No. 32 was playing the App Bugs and Buttons. The child was sitting at an indoor table and to her right was another child, who was watching her play. Child No. 32 was playing a game in which the participant had to correspond numerals to number patterns. In the game there was a beetle with a numeral (e.g., 4) on his shell and three corresponding boxes with decora- 
tion number patterns (e.g., 2, 4 and 6). The child has to select the box with the pattern of 4 and drag the box to the beetle, hence completing the task. Child No. 32 was having difficulty with the task both in terms of how to drag and also the counting component of the task (she made many errors). After 2-3 minutes of playing the game with repeated failures, the child watching Child No. 32 reached in and dragged the appropriate box and smiled at Child No. 32. Child No. 32 glared at the assisting child and pulled the iPad closer to herself. Again Child No. 32 struggled with the game, again the child attempting to assist reached in to help Child No. 32. At this point, Child No. 32 pushed the child's hand away and said "no, this is my turn", the assisting child pulled her hand back and continued to watch Child No. 32.

In this social interaction, both children were engaged in digital play, one as a player and the other as an observer. The observing child initiated help to the player (Child No. 32) by helping drag the appropriate boxes and smiling. However, Child No. 32 rejected the assistance by pushing the child's hand away and verbally refusing help. Child No. 32 stopped the interaction from the other child, and this behaviour is classified as SI6.

\section{SI7: The Player's Private Speech During Playing}

SI7 was categorised if the child was using an iPad and during their play used private speech. This interaction pattern has been found between 0 and 6 times per child observation. Observation of child No. 71 shows an example of this:

Child No. 71 was playing the App Bugs and Bubbles, he had another child sitting next to him. The child was playing a pattern game in which a series of bubbles appears (e.g., yellow, red, yellow, blank), and then a set of three potential answers appears (orange, green, red), and the player has to drag the correct answer to the blank bubbles. Child No.71 was saying the colours out loud: "yellow, red, yellow... [he reached up and dragged the red bubble to the blank space and said:] ...red"! On the next set [blank, purple, orange, purple] he began by repeating the colours "purple, orange, purple", then he put his fingers on the potential answers (orange, purple, blue) and said "noooo...yes" and proceeded to drag the blue bubble to the blank space, which received an error message. Private speech is self-directed speech that is intended to guide thinking and behaviour, which is what Child No. 71 demonstrated in this example.

This example shows no engagement between the children, yet there were words spoken. Child No. 71 demonstrates
Table 2 Frequencies of the 7 social interactions

\begin{tabular}{lllll}
\hline $\begin{array}{l}\text { Social } \\
\text { Interac- } \\
\text { tion }\end{array}$ & $\begin{array}{l}\text { Frequencies } \\
(\mathrm{min})\end{array}$ & $\begin{array}{l}\text { Frequencies } \\
(\max )\end{array}$ & $\begin{array}{l}\text { Frequen- } \\
\text { cies } \\
(\text { Mean })\end{array}$ & $\begin{array}{l}\text { Frequencies } \\
(S D)\end{array}$ \\
\hline 1 & 0 & 6 & 3.43 & 1.55 \\
2 & 0 & 6 & 1.96 & 2.08 \\
3 & 0 & 4 & 1.03 & 1.25 \\
4 & 0 & 3 & 0.18 & 0.57 \\
5 & 0 & 6 & 2.16 & 1.75 \\
6 & 0 & 5 & 1.26 & 1.39 \\
7 & 0 & 6 & 0.98 & 1.92 \\
\hline
\end{tabular}

$\mathrm{N}=80$

Table 3 Correlations between SI1 and persistence, precision, reaction time, satisfaction, energy, facial expression and posture, verbal utterances and language, and general ranking

\begin{tabular}{llr}
\hline Item & $r$ & $p$ \\
\hline Persistence & 0.25 & 0.02 \\
Facial expression and posture & 0.26 & 0.02 \\
Reaction time & 0.39 & $<0.01$ \\
Precision & 0.23 & 0.05 \\
Satisfaction & 0.52 & $<0.01$ \\
Energy & 0.57 & $<0.01$ \\
Verbal utterances and language & 0.37 & $<0.01$ \\
General ranking & 0.46 & $<0.01$ \\
\hline
\end{tabular}

$\mathrm{N}=80$

private speech, by speaking to himself with no social interaction happening. Thus examples where children used private speech to assist in gameplay, with no apparent want/ need for social interaction is classified as SI7.

\section{Frequencies of the 7 Social Interactions}

The seven social interactions happened during the children's play; however, some social interactions happened more frequently than the others did. Table 2 presents the frequencies of each of the social interactions observed among the 80 participating children in each child observation. This shows the most frequently occurring social interactions are SI1 (other children initiate involvement in play), which occurred more than 3 times in each observation, followed by SI5 (the player ignores other children's engagement). The least frequently occurring social interactions were SI4 (the player distracts other children during playing) and SI7 (the player's private speech during playing). 
Table 4 Correlations between SI2 and precision, reaction time, satisfaction, energy, verbal utterances and language, and general ranking

\begin{tabular}{llr}
\hline Item & \multicolumn{1}{l}{$p$} \\
\hline Reaction time & 0.35 & $<0.01$ \\
Precision & 0.27 & 0.01 \\
Satisfaction & 0.39 & $<0.01$ \\
Energy & 0.60 & $<0.01$ \\
Verbal utterances and & 0.52 & $<0.01$ \\
$\quad$ language & & $<0.01$ \\
General ranking & 0.40 &
\end{tabular}

$\mathrm{N}=80$

Table 5 Correlations between SI3 and persistence, precision, reaction time, satisfaction, energy, facial expression and posture, verbal utterances and language, and general ranking

\begin{tabular}{llr}
\hline Item & $r$ & \multicolumn{1}{l}{} \\
\hline Persistence & 0.25 & 0.02 \\
Facial expression and & 0.26 & 0.02 \\
$\quad$ Posture & & \\
Reaction time & 0.39 & $<0.01$ \\
Precision & 0.23 & 0.05 \\
Satisfaction & 0.52 & $<0.01$ \\
Energy & 0.57 & $<0.01$ \\
Verbal utterances and & 0.37 & $<0.01$ \\
$\quad$ Language & & $<0.01$ \\
General ranking & 0.46 &
\end{tabular}

$\mathrm{N}=80$

Table 6 Correlations between SI6 and precision, reaction time, satisfaction and general ranking

\begin{tabular}{lll}
\hline Item & $r$ & $p$ \\
\hline Reaction time & 0.34 & $<0.01$ \\
Precision & 0.33 & $<0.01$ \\
Satisfaction & 0.39 & $<0.01$ \\
General ranking & 0.40 & $<0.01$ \\
\hline
\end{tabular}

$\mathrm{N}=80$

\section{Social Interactions and Involvement in Digital Play}

SI1 (other children initiate involvement in play) was significantly correlated with the following areas in the Involvement Scale (See Table 3). This result emphasised that digital play can be more engaging for the child using the device when they are allowed to play with others, therefore promoting social collaboration between children.
SI2 (the player involves other children in playing) was significantly correlated with the following areas in the Involvement Scale (See Table 4). When the child playing with the iPad initiated an interaction with another child, the playing child's level of engagement went up in seven areas as well as did their overall ranking. Therefore, children's social interaction with digital technology can lead to higher levels of engagement for the playing child during digital play.

SI3 (other children initiate involvement in play) was significantly correlated with the following areas in the Involvement Scale (See Table 5). This result highlights the potential for digital play to be a socially engaging experience. When another child interacted with a child playing with the iPad, the child's level of engagement went up in seven areas, as well as did their overall ranking. Therefore, children's social interaction with digital technology can lead to higher levels of engagement for the child.

SI6 (the player stops other children's interruption) was significantly correlated with the following areas in the Involvement Scale (See Table 6). Whilst the previous two results highlighted children's increased engagement during play with social interaction, this result demonstrates that when children wanted to play with the iPad and stop others interruptions, their engagement levels also improved. Factors such as reaction time and precision were significantly related to stopping interruptions, which indicates that children were focussed heavily whilst engaged in digital play.

\section{Discussion}

This study used observation to investigate young children's engagement levels and various social interaction activities during digital play. The findings showed almost all the areas of engagement other than verbal utterances and language were rated above medium engagement, indicating the social interaction via verbal contact was not strong. This finding is of course, a concern for educators and researchers, when there are already concerns regarding children's language development and communication during the use of digital technology (Plowman \& McPake, 2013; Zabatiero et al., 2018). However, this study found the impact of three social interaction activities on children's engagement levels, with further perspectives on children's social learning. In summary, this study made the following six important contributions related to young children's social learning in their digital play.

First, it was found that peers play an important role in young children's self-confidence and competence in digital play. This aligns with social learning theory, as children develop their social behaviour through communication 
with their peers, their observations of others, and responding to peer instruction and feedback. Children developed their own personal judgement about peers (Chen \& Jiang, 2002; Vahedi et al., 2012), as was shown in SI5 and SI6, where children were able to regulate their own behaviour and that of their peers in order to focus on learning within digital play. Moreover, as was shown in SI2, children are capable and willing to invite peer input to their digital play, which shows children's inner thoughts or self-reflections are shaped by outer social influences (i.e., "I can't do this, can you help me?") and provide "a guide for action" or forethought (Bandura, 2001). Self-reflection influences how children engage within digital play and the ways in which they choose their own course of action.

On multiple occasions parallel play interactions (Buggey \& Ogle, 2013) were observed, which involved less verbalisation or exchange of play equipment; rather, children demonstrated cognitive organisation and self-observation which impacted their level of motivation and reinforcement (Bandura, 2001). This finding shows that traditional forms of play (i.e., sandpit play) are not lost within the integration of digital technologies, but rather are supplemental to them. This finding supports early childhood educators in seeing digital play as a component of a developmentally appropriate program and not as inhibiting social learning (Zabatiero et al., 2018).

Furthermore, children's use of iPad within the current study was done in a play-based setting. In this way it has shown that children do indeed interact socially to modify and complement their own social and emotional development, as well as that of others, whilst interacting with digital technology. As noted in the research context, there were times when teachers made children's use of digital technology a solitary activity, by moving children who were watching or interacting with the playing child. This reflects the educators' ideologies on digital technology rather than the social potential of digital play.

Additionally, it was found there were seven observable social interaction forms in digital play, indicating that modelled and peer support (Bandura, 2001; Bowers-Campbell, 2008) occurred in their active learning. For example, in the first example from SI1, the assisting child supported gameplay without being the actual player, demonstrating that digital play has the ability to establish relationships and co-participation in peer activities (Bandura, 2009; Ladd \& Ladd, 2019). Furthermore, educators should be aware that the absence of verbalisation does not equate to no social interaction. Rather, social interactions and turn-taking beyond speech happen in digital play.

The results within this study also showed there are positive social interactions that impact on higher engagement levels of children's digital play, with two kinds of social interaction standing out as relevant: SI1: other children initiate involvement in play and SI2: player involves other children in play. This finding supports Bowers-Campbell's (2008) assertion that peer support, especially through modelling, is an important part of children's learning process, and social interactions can promote active learning (Sherman \& Kurshan, 2004). Digital play creates opportunities for the children to learn with others where knowledge is shared and implemented into the learning process (Johansson et al., 2018).

Finally, that we were able to align children's digital play with traditional theories on play stages supports the notion that digital play does not differ from traditional play per the impact of modelling and the child's ability to learn and interact socially. The seven forms of social interaction identified did not always happen during children's engagement in digital play. Rather self-reflection influences how children engage within digital play and choose their own courses of action. For example, SI2, SI5, and SI6 showed playing children chose to purposefully involve, ignore, or stop other peers' engagement or interruptions.

\section{Conclusion and Future Studies}

This study investigated the social interactions of eighty children, 3-4 years of age, during digital play by using social learning theory. This study was conducted within three childcare centres in Australia. This study used empirical data and found children were constantly engaged with others during their digital play. We also identified seven different forms of social interaction in digital play, which align with traditional approaches to children play (Buggey \& Ogle, 2013). The study highlighted the potential for digital play to be positioned within early childhood programs as an approach that will not only support children to learn (Disney et al., 2019) but do so in a socially engaging manner.

Limitations of this study are situated within the limited sample size to be generalised to the wider field of early childhood. Future studies should investigate a variety of early childhood service types (e.g., stand-alone kindergartens, family daycare settings) and with extended cultural diverse backgrounds of children and families. Furthermore, the individual personal characteristics of children need to be further investigated when integrating digital play with young children, as well as any additional needs, to create a developmental framework from which digital play can be integrated for all children. How and how often children utilise technologies throughout their life spans, as well as the timing of the cultural climate in history (for example, the impact of COVID-19 on online learning in 
early childhood), shape agency in each child's own learning and development with technology (Rosa \& Tudge, 2013). This will require collaborative work between academics and practitioners to establish "what works" within digital play in early childhood settings. There seem to be a disconnect in terms of what early childhood stakeholders believe to be educational and development concerns related to digital technologies. Thus, further study is also needed to involve and investigate early childhood educators' professional development needs to establish social learning during digital play.

\section{Funding N/A.}

\section{Declarations}

Conflict of interest No potential conflict of interest was reported by the authors.

Ethical Approval An approval from an Australian University Ethics Committee were obtained, information letters and consent forms were distributed among the participants and their parents.

Informed Consent Information letters and consent forms were distributed and obtained among the participants and their parents.

Consent for Publication Consent for publication were obtained among the participants and their parents.

\section{References}

American Academy of Pediatrics. (2011). Media use by children younger than 2 years. Pediatrics, 128(5), 1040-1045. https://doi. org/10.1542/peds.2011-1753

Ary, D., Jacobs, L. C., \& Sorensen, C. (2010). Introduction to research in education. Wadsworth Cengage Learning.

Bandura, A. (1977). Social learning theory. General Learning Press.

Bandura, A. (1978). The self system in reciprocal determinism. The American Psychologist, 33, 344-358.

Bandura, A. (1989). Human agency in social cognitive theory. The American Psychologist, 44(9), 1175-1184. https://doi.org/10. 1037/0003-066X.44.9.1175.

Bandura, A. (2001). Social cognitive theory: An agentic perspective. Annual Review of Psychology., 52, 1-26.

Bandura, A. (2009). Social cognitive theory of mass communication. In J. Bryant \& M. Oliver (Eds.), Media effects (3rd ed., pp. 94-124). Routledge.

Bird, J., \& Edwards, S. (2015). Children learning to use technologies through play: A Digital Play Framework: Children learning to use technologies through play. British Journal of Educational Technology, 46(6), 1149-1160. https://doi.org/10.1111/bjet.12191

Bowers-Campbell, J. (2008). Cyber "pokes": Motivational antidote for developmental college readers. Journal of College Reading and Learning, 39(1), 74-87.

Buggey, T., \& Ogle, L. (2013). The use of self-modeling to promote social interactions among young children. Focus on Autism and Other Developmental Disabilities, 28(4), 202-211.
Chen, Q., \& Jiang, Y. (2002). Social competence and behavior problems in Chinese pre-schoolers. Early Education and Development, 13(2), 171-186. https://doi.org/10.1207/s15566935eed1302_4

Danby, S. J., Fleer, M., Davidson, C., \& Hatzigianni, M. (2018). Digital childhoods across contexts and countries. In S. J. Danby, M. Fleer, C. Davidson, \& M. Hatzigianni (Eds.), Digital childhoods: Technologies and children's everyday lives (pp. 1-14). Singapore: Springer Singapore.

Denzin, N. K., \& Lincoln, Y. S. (2011). The SAGE handbook of qualitative research (4th ed.). SAGE Publications.

Department of Education and Training. (2019). Belonging, being and becoming: The early years learning framework for Australia. Retrieved from https://docs.education.gov.au/node/2632

Department of Children's Services. (2008). Assessing for learning and development in the early years using observation scales: Reflect, respect, relate. DECS Publishing.

Disney, L. (2016). Numeracy learning with digital play in early childhood settings. Unpublished Doctoral dissertation, University of South Australia, Australia.

Disney, L., Barnes, A., Ey, L., \& Geng, G. (2019). Digital play in young children's numeracy learning. Australian Journal of Early Childhood. https://doi.org/10.1177/1836939119832084

Dodge, D. T., Cloker, L. J., \& Heroman, C. (2002). The creative curriculum for preschool. Teaching Strategies.

Donahoo, D. (2018). Unpacking screentime: What should digital technology and early childhood look like? Educating Young Children: Learning and Teaching in the Early Childhood Years, 24(2), 29-31.

Ebbeck, M., Winter, P., Russo, S., Yim, H. Y. B., Teo-Zuzarte, G. L. C., \& Goh, M. (2012). Measuring children's involvement as an indicator of curriculum effectiveness: A curriculum evaluation of a selected child study centre in Singapore. Early Child Development and Care, 182(5), 609-619. https://doi.org/10.1080/03004 430.2011.5663sil29

Edwards, S., Straker, L., \& Oakey, H. (2018). Towards an early childhood Australia statement on young children and digital technology. Retrieved from Early Childhood Australia website. Retrieved from http://www.earlychildhoodaustralia.org.au/wp-content/uploa ds/2017/08/ECA-DPG-Disussion-Paper-April-including-appen dices_FINAL-2.pdf

Edwards, S. (2016). New concepts of play and the problem of technology, digital media and popular-culture integration with play-based learning in early childhood education. Technology, Pedagogy and Education, 25(4), 513-532.

Edwards, S., Henderson, M., Gronn, D., Scott, A., \& Mirkhil, M. (2017). Digital disconnect or digital difference? A socio-ecological perspective on young children's technology use in the home and the early childhood centre. Technology, Pedagogy and Education, 26(1), 1-17.

Flynn, R. M., \& Richert, R. A. (2015). Parents support preschoolers' use of a novel interactive device. Infant and Child Development, 24(6), 624-642. https://doi.org/10.1002/icd.1911

Garvis, S., Phillipson, S., Clarke, S., Harrison, L., McCormack, J., \& Pendergast, D. (2019). Child development and learning. Oxford University Press.

Haugland, S. W. (2000). Computers and young children. Clearinghouse on Elementary and Early Childhood Education.

Johansson, J., Contero, M., Company, P., \& Elgh, F. (2018). Supporting connectivism in knowledge-based engineering with graph theory, filtering techniques and model quality assurance. Advanced Engineering Informatics, 38, 252-263.

Johnson, B., \& Christensen, L. B. (2014). Educational research : Quantitative, qualitative, and mixed approaches (5th ed.). Sage Publications. 
Johnston, K., Highfield, K., \& Hadley, F. (2018). Supporting young children as digital citizens: The importance of shared understandings of technology to support integration in play-based learning. British Journal of Educational Technology, 49(5), 896-910.

Kafai, Y. B., \& Resnick, M. (1996). Constructionism in practice: Designing, thinking, and learning in a digital world. Lawrence Erlbaum Associates.

Ladd, G., \& Ladd, B. K. (2019). Parents and children's peer relationships. In M. H. Bornstein (Ed.), Handbook of parenting: Volume 5: The practice of parenting (3rd ed.). New York: Routledge.

Mantilla, A., \& Edwards, S. (2019). Digital technology use by and with young children: A systematic review for the Statement on Young Children and Digital Technologies. Australasian Journal of Early Childhood, 44(2), 182-195.

Marsh, J., Plowman, L., Yamada-Rice, D., Bishop, J., \& Scott, F. (2016). Digital play: A new classification. Early Years (london, England), 36(3), 242-253. https://doi.org/10.1080/09575146. 2016.1167675

McDevitt, T. M., \& Ormrod, J. E. (2012). Child development and education. Pearson Education.

Parten, M. (1932). A statistical analysis of the modern family. The Annals of the American Academy of Political and Social Science, 160(1), 29-37.

Plowman, L. (2016). Rethinking context: Digital technologies and children's everyday lives. Children's Geographies, 14(2), 190-202. https://doi.org/10.1080/14733285.2015.1127326

Plowman, L., \& McPake, J. (2013). Seven myths about young children and technology. Childhood Education, 89(1), 27-33.

Plowman, L., McPake, J., \& Stephen, C. (2008). Just picking it up? Young children learning with technology at home. Cambridge Journal of Education, 38(3), 303-319. https://doi.org/10.1080/ 03057640802287564

Puerling, B. (2018). Teaching in the digital age for preschool and kindergarten: Enhancing curriculum with technology. Redleaf Press.

Punch, K. (2009). Introduction to research methods in education. SAGE Publications.

Rosa, E. M., \& Tudge, J. (2013). Urie Bronfenbrenner's theory of human development: Its evolution from ecology to bioecology. Journal of Family Theory \& Review, 5(4), 243-258.

Sakr, M. (2019). Digital play in early childhood: What's the problem? SAGE Publication.
Scott, F. L. (April 2021). Digital Technology and Play in Early Childhood. Retrieved from https://www.child-encyclopedia.com/techn ology-early-childhood-education/according-experts/digital-techn ology-and-play-early-childhood

Scott, F. \& Marsh, J. (2018). Digital literacies in early childhood. Oxford Research Encyclopedia of Education. https://doi.org/10. 1093/acrefore/9780190264093.013.97

Sherman, T., \& Kurshan, B. (2004). Teaching for understanding. Learning \& Leading with Technology, 32(4), 6-11.

Silverman, D. (2014). Interpreting qualitative data (5th ed.). SAGE.

Simon, F., Nemeth, K., \& Donohue, C. (2012). Digital decisions. Gryphon House Inc.

Staddon, J. E. R. (1984). Social learning theory and the dynamics of interaction. Psychological Review, 91(4), 502-507.

Straker, L., Zabatiero, J., Danby, S., Thorpe, K., \& Edwards, S. (2018). Conflicting guidelines on young children's screen time and use of digital technology create policy and practice dilemmas. The Journal of Pediatrics, 202, 300-303.

Suen, H. K., \& Ary, D. (2014). Analysing quantitative behavioral observation data. Psychology Press.

Vahedi, S., Farrokhi, F., \& Farajian, F. (2012). Social competence and behavior problems in preschool children. Iranian Journal of Psychiatry, 7(3), 126-134.

Wood, E., Nuttall, J., Edwards, S., \& Grieshaber, S. (2020). Young children's digital play in early childhood settings: Curriculum, pedagogy and teachers' knowledge. In O. Erstad, R. Flewitt, B. Kümmerling-Meibauer, \& Í. S. Pereira (Eds.), The Routledge handbook of digital literacies in early childhood (1st ed., pp. 214-226). Routledge.

Zabatiero, J., Straker, L., Mantilla, A., Edwards, S., \& Danby, S. (2018). Young children and digital technology: Australian early childhood education and care sector adults' Perspectives. Australasian Journal of Early Childhood, 43(2), 14-22. https://doi. org/10.23965/AJEC.43.2.02

Publisher's Note Springer Nature remains neutral with regard to jurisdictional claims in published maps and institutional affiliations. 